\title{
Etiologic profile and antimicrobial susceptibility of community-acquired urinary tract infection in two Cameroonian towns
}

\author{
Jane-Francis Tatah Kihla Akoachere ${ }^{1,2^{*}}$, Suylika Yvonne ${ }^{1}$, Njom Henry Akum ${ }^{2}$ and Esemu Nkie Seraphine ${ }^{2}$
}

\begin{abstract}
Background: Urinary tract infection (UTI) represents one of the most common diseases encountered in community medical practice. In resource poor settings, treatment is usually empiric due to the high cost and long duration required for reporting diagnosis by culture and antibiotic susceptibility testing. With the growing problem of drug resistance knowledge of antibiotic susceptibility pattern is pertinent for successful eradication of invading pathogens. Our study, the first of its kind in Cameroon, analyzed the distribution and antibiotic susceptibility of bacteria causing community-acquired urinary tract infection (CAUTI) in two towns (Bamenda and Buea) with a large number of young and middle aged persons, to provide data that could guide empiric treatment.

Findings: We cultured 235 urine specimens and analyzed the antibiotic susceptibility of isolates by the disc diffusion technique. Uropathogens were recovered from 137 (58.3\%), with prevalence rates in Buea and Bamenda being $65.9 \%$ and 54\% respectively. Predominant pathogens were Escherichia coli (31.4\%), Klebsiella oxytoca (25.5\%) and Staphylococcus spp (24.1\%). Geographic variation in uropathogen distribution and antibiotic susceptibility was observed, and a significant difference in pathogen distribution with respect to gender. The 20-39 years age group had the highest prevalence of infection. All pathogens isolated were detected in this group. Isolates exhibited low susceptibility to antibiotics tested. Bamenda isolates generally exhibited lower susceptibility compared to those from Buea.
\end{abstract}

Conclusion: Regional variation in etiology of CAUTI and antibiotic susceptibility observed in our study emphasizes the need to establish local and national antimicrobial resistance monitoring systems in Cameroon to provide information for the development of CAUTI treatment guidelines.

Keywords: Community-acquired urinary tract infection, Bacteria, Antibiotic susceptibility, Cameroon

\section{Findings}

A total of 235 patients comprising 150 (63.8\%) from Bamenda and 85 (36.2\%) from Buea were sampled. Of these, $167(71.1 \%)$ were females and $68(38.9 \%)$ were males. The age of participants ranged from 2 years to 80 years. Patients were stratified into the following agegroups: $<20$ years $(\mathrm{n}=29,12.3 \%), 20-39$ years $(\mathrm{n}=131$, $55.7 \%), \quad 40-59$ years $(\mathrm{n}=51,21.7 \%)$ and $\geq 60$ years

\footnotetext{
* Correspondence: jakoachere@yahoo.com
'Department of Microbiology and Parasitology, Faculty of Science, University

* Correspondence: jakoachere@yahoo.com
'Department of Microbiology and Parasitology, Faculty of Science, University of Buea, Buea, Cameroon

${ }^{2}$ Laboratory for Emerging Infectious Diseases, Faculty of Science, University of Laboratory for Emerging
Buea, Buea, Cameroon
}

$(\mathrm{n}=24,10.2 \%)$. A total of $137(58.3 \%)$ samples had significant growth of pathogens.

UTI prevalence was $65.9 \%$ in Buea and $54 \%$ in Bamenda (Table 1). Logistic regression analysis of UTI with study site as a predictor produced no significant relationship $(\mathrm{G}=0.161, \mathrm{df}=1, p=0.687)$. Measure of association between prevalence of UTI and study site showed weak predictive ability (Somers' D (0.01) and Goodman-Kruskal Gamma (0.11) are close to zero).

Analyzing prevalence with respect to gender, females (67.7\%) had a higher prevalence of infection than males (35.3\%) (Table 1). UTI prevalence was significantly related to gender $(\mathrm{G}=20.769, \mathrm{DF}=1, \mathrm{P}-$ Value $=0.000)$ with projections of 1.346 higher prevalence in females 
Table 1 Prevalence of infection in study area with respect to gender

\begin{tabular}{llll}
\hline Study Site (Region) & Gender & No. positive & \% positive \\
\hline Bamenda(North West) & Females, $\mathrm{n}=97$ & 65 & $67.0 \%$ \\
\cline { 2 - 4 } & Males, $\mathrm{n}=53$ & 16 & $30.2 \%$ \\
\hline Total & 150 & 81 & $54.0 \%$ \\
\hline Buea(South West) & Females, $\mathrm{n}=70$ & 48 & $68.6 \%$ \\
\cline { 2 - 4 } & Males, $\mathrm{n}=15$ & 8 & $53.3 \%$ \\
\hline Total & 85 & 56 & $65.9 \%$ \\
\hline Grand total & Females, $\mathrm{n}=167$ & 113 & $67.7 \%$ \\
\cline { 2 - 4 } & Males, $\mathrm{n}=68$ & 24 & $35.3 \%$ \\
\cline { 2 - 4 } & Males + females $=235$ & 137 & $58.3 \%$ \\
\hline
\end{tabular}

relative to males. Large values of Somers' D (0.27) and Goodman-Kruskal Gamma (0.59) were associated with this relationship indicating good predictive ability. A combined logistic regression using gender, study site versus UTI showed a significant relationship $(G=23.419$, $\mathrm{DF}=2$, P-Value $=0.000$ ) and good predictive power (Somers' D (0.29), Goodman-Kruskal Gamma (0.58)).

E. coli (31.4\%), K. oxytoca (25.5\%) and Staph. sp (24.1\%) were the predominant isolates associated with UTI while $K$. pneumoniae had the least occurrence (1/81, 1.2\%) (Figure 1).

Gram-positive organisms constituted only $26.3 \%$ of isolates (Table 2). Klebsiella oxytoca was the most frequently isolated organism in Bamenda (29.6\%). This was closely followed by E. coli (28.4\%) and Staph. spp (22.2\%). The predominant pathogen in Buea was E. coli (35.7\%). Streptococcus spp. (3/56, 5.4\%) were isolated only from samples from Buea while Proteus vulgaris $(4 / 81,4.9 \%)$ and $K$. pneumoniae $(1 / 81,1.2 \%)$ were detected only in samples from Bamenda. There was no significant relationship between uropathogen distribution and study site $(\mathrm{G}=1.665, \mathrm{DF}=1, \mathrm{P}$-Value $=0.197)$. Citrobacter freundii, $K$. pneumoniae and Serratia marcescens were isolated only from female participants (Figure 2). Predominant pathogens in females were $E$. coli $(88.4 \%)$, Enterobacter cloacae (85.7\%) and K. oxytoca (80\%) (Figure 2). In males the most frequently isolated organisms were Strep. spp (33.3\%), Pseudomonas aeruginosa (28.6\%) and $P$. vulgaris (25.0\%). All bacteria isolated from males were also isolated from females.

E. coli, E. cloacae, K. oxytoca and Staph. spp were isolated from all age-groups (Table 3). All isolates were detected in the 20-39 years group. With the exception of the 40-59 years group in which the predominant isolate was $K$. oxytoca (40.7\%), E. coli was the predominant isolate in all the other age groups. In addition to $E$. coli (26.7\%), other predominant isolates in the $<20$ years participants were $K$. oxytoca $(26.7 \%)$ and Staph. spp (26.7\%). K. pneumoniae (1.2\%) was isolated solely from 20-39 years age-group. Strata of age gave insufficient evidence for a significant relationship with uropathogens $(\mathrm{G}=0.824, \mathrm{DF}=3, \mathrm{P}-$ Value $=0.844)$. However, the logistic regression coefficient of age strata; 0.040,-0.296, 0.038

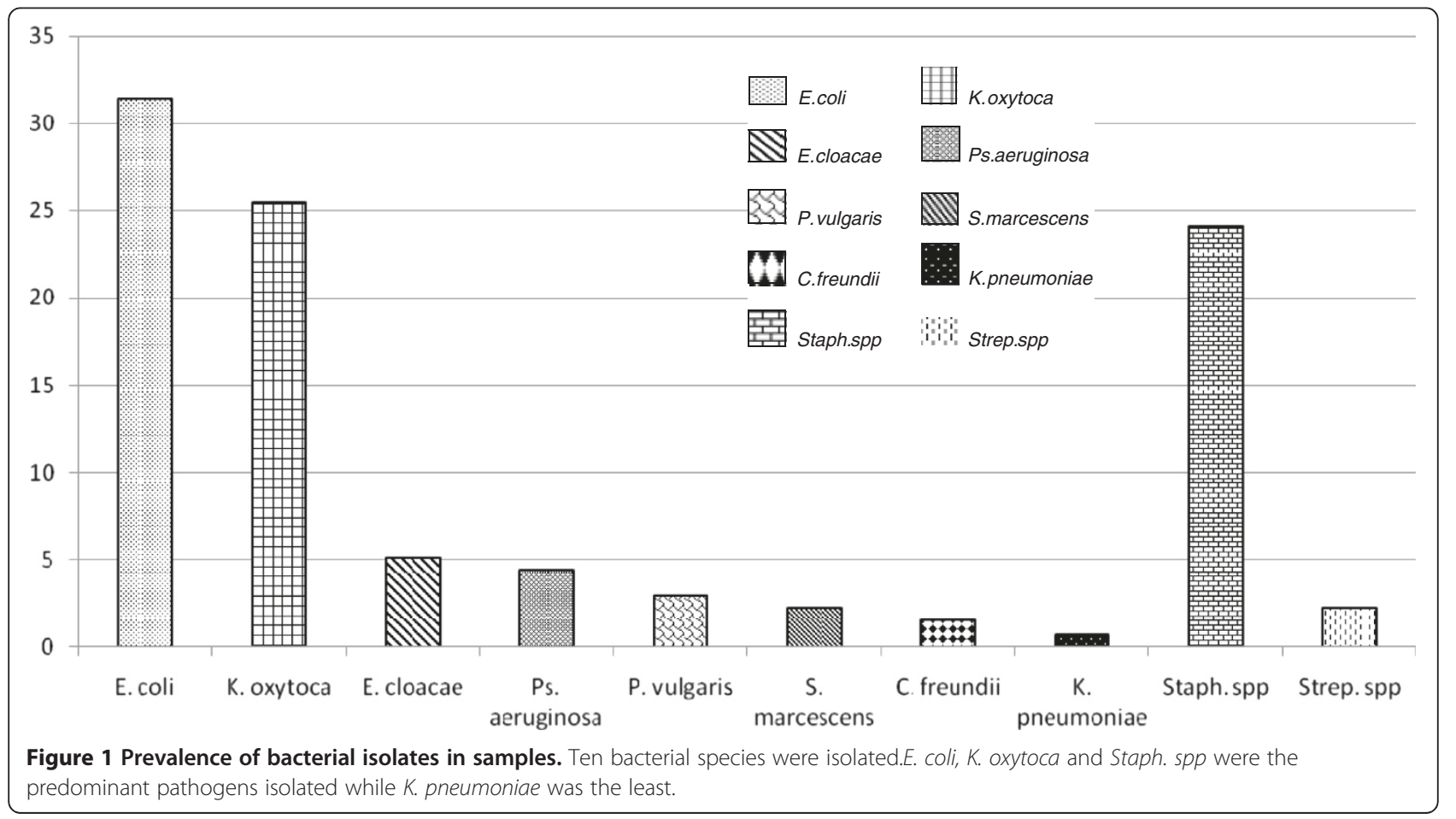


Table 2 Distribution of uropathogens in study sites

\begin{tabular}{|c|c|c|c|c|}
\hline Isolate & Bamenda (\%) & Buea(\%) & Total (\%) & Gram reaction \\
\hline E. coli & $23(28.4)^{*}$ & $20(35.7)^{*}$ & $43(31.4)$ & \multirow{8}{*}{$\begin{array}{l}\text { Gram-negative } \\
n=101(73.7 \%)\end{array}$} \\
\hline K. oxytoca & $24(29.6)$ & $11(19.6)$ & $35(25.5)$ & \\
\hline E. cloacae & $5(6.2)$ & $2(1.8)$ & $7(5.1)$ & \\
\hline Ps. aeruginosa & $3(3.7)$ & $3(5.4)$ & $6(4.4)$ & \\
\hline P. vulgaris & $4(4.9)$ & $0(0.0)^{* *}$ & $4(2.9)$ & \\
\hline S. marcescens & $2(2.5)$ & $1(1.8)$ & $3(2.2)$ & \\
\hline C. freundii & $1(1.2)$ & $1(1.8)$ & $2(1.5)$ & \\
\hline K. pneumoniae & $1(1.2)$ & $0(0.0)^{* *}$ & $1(0.7)$ & \\
\hline Staph. spp & $18(22.2)$ & 15 (26.8) & $33(24.1)$ & \multirow{2}{*}{$\begin{array}{r}\text { Gram-positive } \\
-n=36(26.3 \%)\end{array}$} \\
\hline Strep. spp & $0(0.0)^{* *}$ & $3(5.4)$ & $3(2.2)$ & \\
\hline Total & $81(59.1)$ & $56(40.9)$ & $137(100)$ & \\
\hline
\end{tabular}

*Most prevalent isolate in study site; **Isolated not recovered from study site.

for $20-39,40-59,60+$ respectively showed an increasing uropathogens distribution order of $60+<(<20)<(40-$ $59)<(20-39)$. Both the Pearson and Deviance tests had p-values (0.920 and 0.852 respectively) greater than 0.05 indicating that there was insufficient evidence for the model not fitting the data adequately.

\section{Antimicrobial susceptibility of isolates}

The antimicrobial potency and spectrum of 8 classes of antibiotics against uropathogens is summarized in table 4. Cotrimoxazole was the most inactive drug as isolates showed very low susceptibilities: $12.5 \%$ for Buea and $1.9 \%$ for Bamenda. However, all (100\%) E. coli isolates from Buea were sensitive to the drug. Isolates were also resistant to ampicillin and nitrofurantoin. E. coli isolates from Bamenda were most sensitive to ceftriaxone (65\%) (Table 4). All K. oxytoca isolates from Buea were sensitive to ciprofloxacin (100\%) and gentamicin (100\%) whereas the most potent drugs against the Bamenda isolates were gentamicin (91.2\%), ciprofloxacin (87.5\%) and nitrofurantoin (83.3\%). Isolates generally exhibited susceptibility greater than $50 \%$ to ciprofloxacin except for $S$. marcescens, Strep. spp and E. cloacae from Buea, and C. fruendii from Bamenda which were all (100\%) resistant.

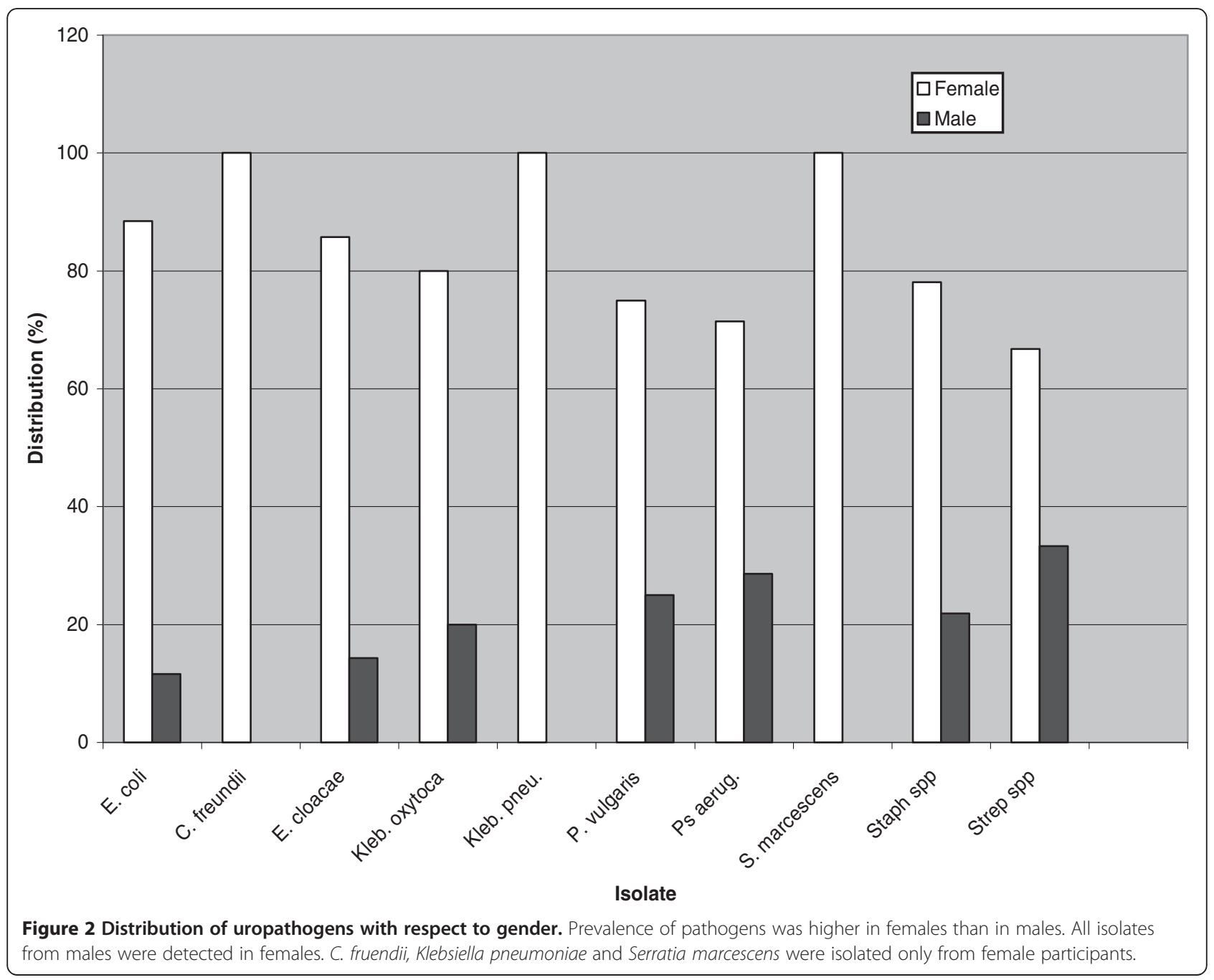


Table 3 Distribution of isolates with respect to age of participants

\begin{tabular}{|c|c|c|c|c|c|}
\hline \multirow[t]{2}{*}{ Isolate } & \multicolumn{5}{|c|}{ Age-group } \\
\hline & $<20(\%)$ & 20-39 (\%) & 40-59 (\%) & $\geq 60$ (\%) & Total (\%) \\
\hline E. coli & $4(26.7)^{*}$ & $29(35.8)^{*}$ & $5(18.5)$ & $5(35.7)^{*}$ & $43(31.4)$ \\
\hline K. oxytoca & $4(26.7)^{*}$ & $17(21)$ & $11(40.7)^{*}$ & $3(21.4)$ & $35(25.5)$ \\
\hline Staph.spp & $4(26.7)^{*}$ & $18(22.2)$ & $6(22.2)$ & $4(28.6)$ & $33(24.1)$ \\
\hline E. cloacae & $1(6.7)$ & $4(4.9)$ & $1(3.7)$ & $1(7.1)$ & $7(5.1)$ \\
\hline Ps. aeruginosa & $0^{* *}$ & $3(3.7)$ & $2(7.4)$ & $1(7.1)$ & $6(4.4)$ \\
\hline P. vulgaris & $0^{* *}$ & $3(3.7)$ & $1(3.7)$ & $0^{* *}$ & $4(2.9)$ \\
\hline S. marcescens & $0^{* *}$ & $2(2.5)$ & $1(3.7)$ & $0^{* *}$ & $3(2.2)$ \\
\hline Strep. Spp & $1(6.7)$ & $2(2.5)$ & $0^{* *}$ & $0^{* *}$ & $3(2.2)$ \\
\hline C. freundii & $1(6.7)$ & $1(1.2)$ & $0^{* *}$ & $0^{* *}$ & $2(1.5)$ \\
\hline K. pneumoniae & $0^{* *}$ & $1(1.2)$ & $0^{* *}$ & $0^{* *}$ & $1(0.7)$ \\
\hline
\end{tabular}

\begin{tabular}{llllll}
\hline Total & $15(10.9)$ & $81(59.1)$ & $27(19.7)$ & $14(10.2)$ & $137(100)$
\end{tabular}

*Most prevalent pathogen in age group; **Pathogen not detected in age group.

Overall, isolates from Buea showed highest susceptibility to gentamicin $(80.9 \%)$ whereas ciprofloxacin $(65.0 \%)$ was the most active agent against Bamenda isolates. With a few exceptions, Bamenda isolates generally exhibited lower susceptibilities than Buea isolates.

\section{Background}

Urinary tract infection (UTI) is the second most common infectious presentation in community medical practice. Worldwide, about 150 million people are diagnosed with UTI each year costing the global economy in excess of 6 billion dollars [1]. The incidence of these infections among young sexually active women has been reported to exceed 0.5 episodes per year [2] with 20 to $30 \%$ of women experiencing recurring infections. During reproductive life this infection represents a great amount of work disabilities, hence the need for prophylaxis and prompt treatment. Most of the UTI seen in women are uncomplicated (occurring in otherwise healthy individuals without any metabolic, functional or anatomic abnormality of the urinary tract). However, after middle age, the prevalence and incidence of UTI increase progressively in men with a concomitant and progressive decrease in the male-to-female ratio [3]. Major contributing factors for high levels of UTIs particularly in rural areas are poor sanitary conditions and lack of proper hygiene.

Reporting of antimicrobial susceptibility testing of the urinary tract is usually achieved $48 \mathrm{~h}$ following sampling, and therefore, in the majority of community-acquired UTI (CAUTI), treatment decision is empiric, based on the limited and predictable spectrum of etiological microorganisms and available data reflecting antibiotic resistance. Furthermore, in most cases, culture and susceptibility testing costs more than antibiotic treatment itself. These factors have complicated empiric treatment of CAUTI as data on uropathogens prevalence and antimicrobial susceptibility becomes more difficult to obtain. Considering the fact that as with many community-acquired infections, resistance rates to antimicrobials commonly used in treatment of UTI is increasing and susceptibility of microorganisms shows significant geographical variations [4], studies to increase knowledge on etiologic agents of UTIs and their resistance patterns to antibiotics at the local and national levels are very important to guide clinicians in empiric treatment.

The etiology and resistance pattern of communityacquired uropathogens has not been extensively studied in Cameroon. Due to the high cost associated with diagnosis of UTI by culture, laboratory diagnosis of UTI in most health care facilities is mainly by urinalysis and urine microscopy. Although the etiology of UTI is predictable, determination of antimicrobial susceptibility pattern of pathogens is unattainable with these techniques. Therefore treatment of UTI is mainly empiric, without knowledge of antibiotic susceptibility of invading pathogen. With the growing problem of drug resistance in Cameroon as demonstrated by recent studies $[5,6]$ there is an urgent need for continuous surveillance of antibiotic susceptibility of uropathogens. Appropriate knowledge of local and national antimicrobial resistance trends is of utmost importance in order to step up evidence based recommendations in empiric antibiotic treatment of UTI. Data on etiology of UTI as well as local and national antimicrobial susceptibility of uropathogens in Cameroon is scarce. This study was aimed at analyzing the distribution of species of bacterial pathogens associated with community-acquired UTI in patients in two Cameroonian towns: Bamenda (North West region) and Buea (South West region) and to determine their susceptibility to commonly prescribed antibiotics so as to generate data that could be helpful in improving the efficacy of empiric treatment of UTI. These towns were selected because of their location in distinct geographic regions and also because they host many educational institutions and as such have a large number of young and middle age individuals. Findings would also be helpful when formulating policies on antibiotic prescription.

\section{Methods \\ Study area}

The study was carried out in Bamenda and Buea. Bamenda is the capital city of North West (NW) region and has a population of over 269,530 . It is characterized by high relief, cool temperatures (particularly in the dry season), heavy rainfall and savanna vegetation. Buea, the capital of the South West (SW) region is located on the eastern slopes of Mount Cameroon and has a population of over 200,000. Because of its location at the foot of Mount Cameroon, it has tropical and mountain 
Table 4 Antibiotic susceptibility of isolates from each region (\%)

\begin{tabular}{|c|c|c|c|c|c|c|c|c|c|c|c|c|c|c|}
\hline \multirow{2}{*}{$\begin{array}{l}\text { ISOLATE } \\
\text { E. coli }\end{array}$} & \multicolumn{2}{|c|}{$\begin{array}{c}\text { AMP } \\
\text { BU BD }\end{array}$} & \multicolumn{2}{|c|}{$\begin{array}{c}\text { CIP } \\
\text { BU BD }\end{array}$} & \multicolumn{2}{|c|}{$\begin{array}{c}\text { COT } \\
\text { BU BD }\end{array}$} & \multicolumn{2}{|c|}{$\begin{array}{c}\text { ERY } \\
\text { BU BD }\end{array}$} & \multicolumn{2}{|c|}{$\begin{array}{l}\text { GEN } \\
\text { BU BD }\end{array}$} & \multicolumn{2}{|c|}{$\begin{array}{c}\text { NIT } \\
\text { BU BD }\end{array}$} & \multicolumn{2}{|c|}{$\begin{array}{c}\text { CEF } \\
\text { BU BD }\end{array}$} \\
\hline & 93.3 & 26.1 & 100 & 52.2 & 100 & 17.4 & 100 & 39.1 & 80 & 43.5 & 20 & 43.5 & 35 & 65 \\
\hline K. oxytoca & 36.4 & 36.4 & 100 & 87.5 & 0 & 0 & 0 & 29.2 & 100 & 91.2 & 90.9 & 83.3 & 18.2 & 75 \\
\hline Staph. sp & 40 & 77.7 & 80 & 55.6 & 0 & 0 & 33.3 & 55.6 & 66.7 & 55.6 & 40 & 66.7 & 53.3 & 72.2 \\
\hline E. cloacae & 100 & 0 & 0 & 80 & 0 & 0 & 100 & 50 & 100 & 80 & 0 & 80 & 100 & 100 \\
\hline P. aeruginosa & 0 & 66.7 & 100 & 100 & 0 & 0 & 0 & 0 & 100 & 100 & 100 & 66.7 & 66.7 & 100 \\
\hline P. vulgaris & ND & 0 & ND & 50 & ND & 0 & ND & 50 & ND & 25 & ND & 50 & ND & 25 \\
\hline S. marcescens & 0 & 50 & 0 & 100 & 0 & 0 & 100 & 0 & 100 & 100 & 0 & 50 & 0 & 50 \\
\hline Strept. spp & 100 & $\mathrm{ND}$ & 0 & ND & 0 & $\mathrm{ND}$ & 100 & $\mathrm{ND}$ & 100 & $\mathrm{ND}$ & 0 & ND & 100 & $\overline{N D}$ \\
\hline C. fruendii & 0 & 0 & 100 & 0 & 0 & 0 & 0 & 100 & 0 & 100 & 0 & 0 & 0 & 0 \\
\hline K. pneumoniae & ND & 0 & ND & 100 & ND & 0 & ND & 0 & ND & 0 & ND & 0 & ND & 0 \\
\hline Mean \% & 46.2 & 28.5 & 60 & 65.0 & 12.5 & 1.9 & 54.2 & 36.0 & 80.8 & 55.1 & 31.4 & 48.9 & 46.7 & $\overline{54.1}$ \\
\hline
\end{tabular}

BU- Buea; BD-Bamenda; ND-Not determined as isolate was not recovered from study site; AMP-Ampicillin; CIP-Ciprofloxacin; COT-Cotrimoxazole; ERY-Erythromycin; GEN- Gentamicin; NIT- Nitrofurantoin; CEF- Ceftriaxone.

rainforest as well as savanna vegetation. The climate is humid. Extended periods of rainfall, characterized by incessant drizzle and damp fogs are common during the rainy season. Buea and Bamenda are located $222 \mathrm{~km}$ apart.

\section{Study design, data collection and patients}

This study was based on laboratory investigations with urine samples collected from all hospitalized and outpatients (those for which urinalysis was requested) in selected hospitals in Bamenda and Buea between 01 March, 2009 and 28 February, 2010. Participating hospitals were chosen due good patient turn out. The study included all patients having clinical evidence of UTI with symptoms less than 7 days presenting at the out-patient department of hospitals and those admitted for less than $48 \mathrm{~h}$. All patients sampled gave consent to participate in the study. Patients with pregnancy, complicating factors such as upper UTI, urinary abnormalities or more than three episodes of UTI in the previous year were excluded. Also excluded from this study were patients with clinical symptoms of UTI but whose samples showed no growth and those who underwent antibiotic treatment within $48 \mathrm{~h}$. Patients' demographic data, symptoms and physical examination were collected using a questionnaire. Only one sample was collected from each patient. Ethical approval of the study was obtained from participating hospitals (Bamenda Regional Hospital, St. Mary Health Center Bamenda, Regional Hospital Annex Buea and Mount Mary Health Center Buea) and from the Northwest and Southwest Regional Delegations of Public Health.

\section{Sample collection and analysis}

Fifty milliliters of clean-catch midstream urine specimen was collected in a sterile Dynarex specimen container.
Twenty-five milliliters was used in this study and the rest of the sample was used by the hospital laboratory for urinalysis. The semi-quantitative technique to determine significant bacteriuria was employed by using $0.01 \mathrm{~mL}$ calibrated wire loop to inoculate $5 \%$ blood agar and Eosine-Methylene Blue (EMB) agar with uncentrifuged urine. Culture plates were incubated at $37^{\circ} \mathrm{C}$ for $18-24 \mathrm{~h}$. After inoculation of media, the remaining sample was centrifuged at $2000 \mathrm{rpm}$ for 5 minutes and sediment used for microscopy. A specimen was considered positive if a single organism was isolated at a concentration of greater than $10^{5} \mathrm{CFU} / \mathrm{mL}$ and associated with microscopy findings of greater than 10 leucocytes per high power field. Bacteria were identified by Gram's stain and standard biochemical procedures. Identity of enterobacteriaceae was confirmed using the API 20E kit.

\section{Antibiotic susceptibility testing}

Susceptibility of isolates to antimicrobial agents of different classes was assessed by the disk diffusion technique on Mueller-Hinton agar as described by the National Committee for Clinical Laboratory Standards (presently called Clinical Laboratory Standard Institute) [7]. The following antibiotics used for empiric treatment were analyzed: erythromycin $(15 \mu \mathrm{g} / \mathrm{mL})$, gentamicin $(10 \mu \mathrm{g} / \mathrm{mL})$, trimethoprim/sulfamethoxazole $(2.5 \mu \mathrm{g} / \mathrm{mL})$, nitrofurantoin $(50 \mu \mathrm{g} / \mathrm{mL})$, ampicillin $(25 \mu \mathrm{g} / \mathrm{mL})$, ceftriazone $(10 \mu \mathrm{g} / \mathrm{mL})$, ciprofloxacin $(5 \mu \mathrm{g} / \mathrm{mL})$ and pefloxacin $(10 \mu \mathrm{g} / \mathrm{mL})$ (Oxoid, Basingstoke, England).

\section{Statistical analysis}

Data from study was inserted into two separate MS Excel spreadsheets that were later on merged to ensure correct data entry, coded and imported into Minitab 16 for statistical analysis. Logistic regression was used to test the relationship between predictors (variables in the 
study) and urinary tract infections (UTI) using p-values of the G statistics at an $\alpha$-level of 0.05. Coefficients of factor levels were used for comparative analysis relative to reference factors. Goodness-of-fit statistics was used to compare the fits of different models. Measure of association was used between predicted probabilities and the response variable to test the predictive ability of the model. Descriptive statistics was employed to weigh the outcome of variables.

\section{Discussion}

Urinary tract infections (UTIs) represent one of the most common diseases encountered in medical practice, causing significant associated morbidity and occurring from neonate to the elderly [8]. Studies [9] have demonstrated geographic variation in etiologic characteristics of UTI and their resistance patterns to antibiotics. Therefore to successfully eradicate UTI by empiric treatment, knowledge of local etiologic agents and their antibiotic susceptibility is of great value. This study reports the etiologic agents of CAUTI and their antibiotic susceptibility in two Cameroonian cities located $222 \mathrm{~km}$ apart in two distinct geographic regions, and provides baseline data which could help in the establishment of local guidelines for treatment of CAUTI. Patients sampled were from the communities where the participating hospitals serve as main primary care centers.

Of the 235 suspected cases of UTI that were positive by microscopy (greater than 10 leucocytes per high power microscope field), only 137 (58.3\%) were positive by culture (Table 1). Although the presence of white blood cells in urine signifies inflammation, based on our results, they do not always indicate UTI. Our findings therefore indicate that urine culture is essential for definitive diagnosis of UTI. The prevalence rate in Buea (65.9\%) was higher than $54.0 \%$ recorded in Bamenda. In a similar study in Buea, Assob et al. [10] analyzed 53 urine samples from patients with UTI and reported a prevalence rate of $49.06 \%$. Logistic regression analysis showed no relationship between UTI prevalence and study site $(\mathrm{G}=0.161, \mathrm{df}=1, p=0.687)$. Values reported in our study are higher than $35.2 \%$ reported by Yuyun et al. [11] in Yaounde, Cameroon. Prevalence rates reported in Cameroon are higher than values reported in other developing countries such as Senegal, 8.45\% [12], Cambodia 22.53\% [13], Latin America 29.9\% [14], Rwanda, 19.3\% [15] and India 10.86\% [16] and 9.17\% [17]. Thus UTI could be a significant cause of morbidity in Cameroon. Although UTI ranks among the most common infections in developing countries we sampled only 235 participants. In addition to the fact that uncomplicated UTIs are generally self-limiting, patients are usually concerned about the social stigma associated with UTI as such prefer unorthodox treatment or self medication. These factors could explain our small sample size.

UTI prevalence was higher in females $(67.7 \%)$ than in males (35.3\%) (Table 1). The prevalence of UTI was significantly related to gender $(G=20.769, D F=1, \quad P$ Value $=0.000$ ). The highest occurrence was in the age group $20-39$ years $(81 / 137,59.1 \%)$ followed by participants $40-59$ years old $(27 / 137,19.7 \%)$ (Table 3$)$. This is in agreement with previous studies [16] which have demonstrated a high prevalence of UTI in individuals less than 50 years of age. However, recent studies [18] have associated older age with higher morbidity. The age group 20-39 years is the most sexually active group of the population and their activities predispose them to UTI. Most women of child-bearing age fall within this group. Thus, during reproductive life, UTI could cause a great amount of disabilities. The propensity of young women to develop UTI has been explained on the basis of their anatomy (especially a short urethra) and certain behavioral factors [19].

Gram negative organisms (73.7\%) (Table 2) were the main cause of UTI in our study sites with $E$. coli (31.4\%) being the predominant pathogen while $K$. pneumoniae was the least (1.2\%) (Figure 1). UTI etiology as well as the predominance of $E$. coli as a leading cause of CAUTI reported in our study has been well documented in reports from other parts of the world such as the ECO SENS report from Europe and Canada [20], and The Surveillance Network (TSN) study from the United States [21] as well as numerous reports from developing countries [22,23]. The low prevalence of $K$. pneumoniae in cases of CAUTI is consistent with previous studies [24]. Although E. coli, K. oxytoca and Staph. spp were the principal uropathogens in our study sites, there was a remarkable variation in distribution of other etiologic agents between study sites. P. vulgaris (4.9\%) and $K$. pnuemoniae (1.2\%) were isolated only from samples collected from Bamenda whereas Strep. spp (5.4\%) was detected solely in Buea samples. Even though the prevalence of these isolates was low, our data suggests evolution in uropathogen etiology and emphasizes the need for periodic assessment of uropathogens and their antibiotic susceptibility pattern at local and national level to guarantee successful empiric treatment. Due to the large number of isolates obtained from this study, we were unable to characterize the Gram positive isolates to permit their identification to species level. This constitutes a limitation to this study. All uropathogens predominated in females than in males (Figure 2). In addition we observed variation in distribution of etiologic agents with gender and age (Figure 2, Table 3). C. fruendii, $K$. pneumoniae and $S$. marcescens were isolated solely from females. All isolates were recovered from the age group 20-39 years whereas in participants over 60 years old, 
only $50 \%(5 / 10)$ of species were detected. Strata of ages gave insufficient evidence for a significant relationship with uropathogens $(\mathrm{G}=0.824, \mathrm{DF}=3, \mathrm{P}$-Value $=0.844)$. However, the logistic regression coefficient of age strata; $0.040,-0.296,0.038$ for $20-39,40-59,60+$ respectively showed an increasing uropathogens distribution order of $60+<(<20)<(40-59)<(20-39)$.

Our data demonstrates low susceptibility to first line agents and regional variation in antibiotic susceptibility pattern. Generally, ampicillin, cotrimoxazole and nitrofurantoin were the most inactive drugs as they exhibited susceptibilities less than $50 \%$ in both study sites. These low susceptibilities limit their usefulness in the treatment of UTI. All isolates were resistant (100\%) to cotrimoxazole except $E$. coli with susceptibilities of $100 \%$ and $17.4 \%$ respectively for the Buea and Bamenda isolates. Other studies on community-acquired UTI [16] have reported low susceptibility of $E$. coli to cotrimoxazole. Although the Infectious Disease Society of America (IDSA) guidelines consider cotrimoxazole for empiric treatment of UTI [25], the low susceptibility recorded in our study $(12.5 \%$ and $1.9 \%$ respectively for Buea and Bamenda isolates) shows that cotrimoxazole is not appropriate for empiric treatment of UTI in study sites but could be a suitable agent for eradication of $E$. coli infections in Buea. Susceptibility of E. coli to other antibiotics was lower than reported in other African countries $[26,27]$. K. oxytoca generally showed low susceptibility to antibiotics with the exception of ciprofloxacin, gentamicin and nitrofurantoin with susceptibilities more than $87 \%$ in both study sites. For Staph spp, ciprofloxacin $(80 \%)$ was most effective against Buea isolates while for the Bamenda isolates, ampicillin (77.7\%) and ceftriaxone (72.2\%) were the most potent agents. We did not include a control strain in susceptibility testing. In addition, we did not determine the minimum inhibitory concentration (MIC) of potent antibiotics. These are other limitations to this study. The most inactive drugs were ampicillin, cotrimoxazole and nitrofurantoin with overall susceptibilities $<50 \%$. Higher susceptibilities to these drugs have been reported in Europe [28]. Low susceptibilities recorded in our study could be due to the fact that these antibiotics have been extensively used in the treatment of community-acquired UTIs and other infections in the past years in these regions. Most antibiotics tested are oral antibiotics which usually achieve high urinary concentrations and are therefore believed to be potent. Low susceptibilities observed indicate the need for antibiotic susceptibility testing to circumvent treatment failure. Although no reliable data exists, it is well known that many persons in study sites self-medicate, suggesting uncontrolled consumption of these antimicrobial agents particularly as they are cheap. Furthermore the implementation of policy on sale of antibiotics in study sites is weak: many unauthorized persons sell drugs and in pharmacies sale is not restricted exclusively to those with prescription. These factors could contribute to emergence of resistance. The IDSA guideline recommends a bench mark of $10-20 \%$ resistance at which first-line empiric therapy should be modified [25]. Thus, gentamicin with an overall susceptibility of $80.8 \%$ could be appropriate for empiric treatment of UTI in Buea. Most hospitals in study sites are small and usually do not admit patients who are not critically ill. Outpatients prescribed treatments with drugs such as gentamicin which is formulated as injection either return to the hospital for treatment as required or they get assistance from trained nurse in their neighborhood. None of the antibiotics tested is suitable for use in empiric eradication of UTIs in Bamenda. Thus urine cultures are necessary since treatment failure with empiric therapy is likely to occur. In addition studies with other antibiotics not included in our investigation may establish effective agent (s) against Bamenda isolates.

\section{Conclusion}

Our findings demonstrate regional variation in UTI etiology as well as their antibiotic susceptibility emphasizing the need to establish local and national antimicrobial resistance monitoring systems in Cameroon to provide information for the development of CAUTI treatment guidelines. To the best of our knowledge, this is the first report in Cameroon that describes the etiology of community-acquired UTI and their antibiotic susceptibility in two distant localities.

\section{Abbreviations}

IDSA: Infectious Disease Society of America; TSN: The Surveillance Network.

\section{Competing interests}

The authors declare that they have no competing interests.

\section{Author's contributions}

JTKA as principal investigator conceived, designed and coordinated the study, interpreted data and initiated the writing of the manuscript. SY collected samples, isolated and characterized bacteria. NHA carried out antimicrobial susceptibility testing and interpretation of data. ENS assisted in interpretation of data and drafting the manuscript. All authors read and approved the final version of the manuscript.

\section{Acknowledgement}

We thank the North West and South West Regional Delegations of Public Health and the participating hospitals for approving this study. We appreciate the collaboration received from hospital staff. We are grateful to Dr. Clement Jules Assob for reviewing the manuscript. This work was carried out in the Laboratory for Emerging Infectious Diseases at the University of Buea and partially supported by the University of Buea in terms of some of the reagents used.

Received: 31 January 2012 Accepted: 19 April 2012

Published: 7 May 2012

\section{References}

1. Gonzalez CM, Schaeffer AJ: Treatment of urinary tract infection: what's old, what's new, and what works. World J Urol 1999, 6:372-382. 
2. Hooton TM, Scholes D, Hughes JP, Winter C, Roberts PL, Stapleton AE, Stergachis A, Stamm WE: A prospective study of risk factors for symptomatic urinary tract infection in young women. N Engl J Med 1996, 335:468-474

3. Kunin CM: Urinary tract infections in females. Clin Infect Dis 1994, 18:1-12.

4. Gupta K, Scholes D, Stamm WE: Increasing prevalence of antimicrobial resistance causing acute uncomplicated cystitis in women. J Am Med Assoc 1999, 281:736-738.

5. Ndip RN, Dilonga HM, Ndip LM, Akoachere J-FTK, Nkuo-Akenji T: Pseudomonas aeruginosa isolates recovered from clinical and environmental samples in Buea, Cameroon: current status on antibiotyping and antibiogram. Trop Med Int Health 2005, 10(1):74-81.

6. Nkwelang G, Akoachere J-FTK, Kamga LH, Emmanuel DF, Ndip RN: Staphylococcus aureus isolates from clinical and environmental samples in a semi-rural area of Cameroon: phenotypic characterization of isolates. Afr J Microbiol Res 2009, 3(11):731-736.

7. National Committee for Clinical Laboratory Standards: Methods for Disk Susceptibility Test for Bacteria that grow Aerobically, Volume NCCLS Document M2-A7. National Committee for Clinical Laboratory Standards 7th edition. Wayne.

8. Eliana BMG, Berezin EN, Nigro S, Nataly AS, Benini V, Toporovski J: Antibiotic resistance patterns of pediatric community-acquired urinary tract infections. Braz J Infect Dis 2008, 12(4):321-323.

9. Gupta K: Emerging antibiotic resistance in urinary tract pathogens. Infect Dis Clin North Am 2003, 17:243-259.

10. Assob NJC, Weledji EP, Njunda AL, Bolimo F, Asongalem EA, Kamga FHL, Achidi EA, Penlap BV, Ndumbe PM: Bacteriological and mycological characterization of some pathogens of the urogenital tract in Buea subdivision (South West Region Cameroon). Health Sci \& Dis 2009, 10:10-16.

11. Yuyun MF, Angwafo FF III, Koulla-Shiro S, Zoung-Kanyi J: Urinary tract infections and genitourinary abnormalities in Cameroonian men. Trop Med Int Health 2004, 9(4):520-525.

12. Dromigny JA, Nabeth P, Juergens-Behr A, Perrier-Gros-Claude JD: Risk factors for antibiotic-resistant community acquired urinary tract infections in Dakar, Senagal. J. Antimicrob Chemother 2005, 56:236-239.

13. Ruppe E, Hem S, Lath S, Gautier V, Ariey F, Sarthou J-L, Mochy D, Ariet G: CTX-M $\beta$-lactamases in Escherichia coli from community-acquired urinary tract infections, Cambodia. Emerg Infect Dis 2009, 15(5):741-748.

14. Bours PH, Polak R, Hoepelman AIM, Delgado E, Jarquin A, Matute AJ: Increasing resistance in community-acquired urinary tract infections in Latin America, five years after the implementation of national therapeutic guidelines. Int J Infect Dis 2010, 14(9):e770-e774.

15. Muvunyi CM, Masaisa F, Bayingana C, Mutesa L, Musemakweri A, Muhirwa G, Claeys GW: Decreased susceptibility to commonly used antimicrobial agents in bacterial pathogens isolated from urinary tract infections in Rwanda: Need for new antimicrobial guidelines. Am J Trop Med Hyg 2011, 84(6):923-928.

16. Akram M, Shahid M, Khan A: Etiology and antibiotic resistance patterns of community acquired urinary tract infections in JNMC Hospital Aligarh, India. Ann Clin Microb Antimicrob 2007, 6:4. doi:http://dx.doi.org/10.1186/ 1476-0711-6-4

17. Eshwarappa M, Dosegowda R, Aprameya IV, Khan MW, Kumar PS, Kempegowda P: Clinico-microbiological profile of Urinary tract Infection in South India. Indian J Nephrol 2011, 21(1):30-36.

18. Al-Hasan MN, Eckel-Passow JE, Baddour LM: Bacteremia in complicating gram-negative urinary tract infections: a population-based study. $J$ Infect 2010, 60(4):278-285.

19. Manges AR, Natarajan P, Solberg OD, Dietrich PS, Riley LW: The changing prevalence of drug resistant Escherichia coli clonal groups in a community: evidence for community outbreaks of urinary tract infections. Epidemiol Infect 2006, 134:425-432.

20. Kalmeter G: An international survey of the antimicrobial susceptibility of pathogens from uncomplicated urinary tract infections: the ECO.SENS Project. J Antimicrob Chemother 2000, 51:69-79.

21. Gupta K, Hooton TM, Stamm WE: Increasing antimicrobial resistance and the management of uncomplicated community-acquired urinary tract infections. Ann Inter Med 2001, 135:41-50.

22. Kothari A, Sagar V: Antibiotic resistance in pathogens causing community-acquired urinary tract infections in India: a multicenter study. J Infect Dev Countries 2008, 2(5):354-358.
23. Mashouf RY, Babalhavaeji H, Yousef J: Urinary tract infections: bacteriology and antibiotic resistance patterns. Indian Pediatr 2009, 46:617-620.

24. Kumar MS, Lakshmi V, Rajagopalan R: Occurrence of extended spectrum beta-lactamases among Enterobacteriaceae spp isolated at a tertiary care institute. Indian J Med Microbiol 2006, 24(3):208-211.

25. Warren JW, Abrutyn E, Hebel JR, Schaeffer AJ, Stamm WE: Guidelines for antimicrobial treatment of uncomplicated acute bacterial cystitis and acute pyelonephritis in women. Clin Infect Dis 1999, 29:745-759.

26. Bloomberg B, Olsen BE, Hinderaker CG, Langeland N, Gasheka P, Jureen R, Kvåle G, Midtvedt T: Antimicrobial resistance in urinary bacterial isolates from pregnant women in rural Tanzania: implications for public health. Scand J Infect Dis 2005, 37(4):262-268.

27. Sire JM, Nabeth P, Perrier-Gros-Claude JD, Bahsoun I, Siby T, Macondo EA, Gaye-Diallo A, Guyomard S, Seck A, Breurec S, Garin B: Antimicrobial resistance in outpatient Escherichia coli urinary isolates in Dakar, Senegal. $J$ Infect DevCountries 2007, 1(3):263-268.

28. Kalmeter G: An international survey of the antimicrobial susceptibility of pathogens from uncomplicated urinary tract infections: the ECO.SENS Project. J Antimicrob Chemother 2003, 52:69-76.

doi:10.1186/1756-0500-5-219

Cite this article as: Akoachere et al:: Etiologic profile and antimicrobial susceptibility of community-acquired urinary tract infection in two Cameroonian towns. BMC Research Notes 2012 5:219.

\section{Submit your next manuscript to BioMed Central and take full advantage of:}

- Convenient online submission

- Thorough peer review

- No space constraints or color figure charges

- Immediate publication on acceptance

- Inclusion in PubMed, CAS, Scopus and Google Scholar

- Research which is freely available for redistribution 